\title{
A Preliminary Comparison of Semen Quality between Competing and Non-Competing Equine Stallions
}

\section{Megan Wilson and Anke Twigg-Flesner*}

Performance in Equestrian Sport Research Group, Hartpury University Centre, Hartpury College, Gloucestershire, GL19 3BE, UK

\begin{abstract}
Rationale: Artificial insemination allows sport horse stallions within breeding programmes to breed and compete concurrently. The level of exercise of stallions complete during the breeding season is a controversial subject. Daily exercise at low intensities is important for the mental and reproductive well-being of the stallion, however higher intensities of exercise, as seen in competing stallions, may have detrimental effects on seminal quality. The purpose of this study was to gain a greater understanding into the effects of competition and discipline on equid stallion semen through analysis of seminal parameters. The identification of optimal competition management for breeding stallions may lead to increased stallion fertility and economic gain.

Methods: This retrospective study evaluated the seminal data of 1130 stallion collections from two UK based stud farms between 2009 and 2015. Seminal volume, concentration and progressive motility were analysed for differences between competing and non-competing stallions, then for differences between stallion disciplines.

Results: Competing stallion semen concentration and progressive motility was significantly lower than noncompeting stallions $(p<0.05)$. Semen volume was significantly higher in competing stallions $(p<0.05)$ than noncompeting stallions. Non-competing stallion semen count was significantly higher than that of competing stallions $(p<0.05)$.

Conclusion: The difference in semen quality between competing and non-competing stallions, as well as the difference between disciplines suggests endocrinological and physiological changes occur in relation to training intensity and competition. Further research into semen quality considering exercise and competition will allow for contextualisation as to why these differences occurred.
\end{abstract}

Keywords: Stallion; Semen; Equine breeding; Semen quality

\section{Introduction}

Within equine breeding programmes, some stallions are noncompeting or retired from competition, but the majority of sport horse stallions are expected to breed and compete concurrently, which increases their value within reproduction through sporting achievements [1-3]. Stallion competition performance within any discipline is considered one of the main criterion for breeding potential, with many stallions put through intensive performance testing before being accepted into stud books [4]. Clients often prefer stallions that are consistently performing at high levels within the competition sphere, with the intention of increasing genetic progress and ultimately obtaining high achieving offspring [5]. The increasing concentration on performance could however lead to reduced reproductive viability in stallions as impacts on the reproductive physiology and psychology be overlooked [6,7].

Daily exercise is thought to be important for the mental and reproductive well-being of stallions [8-10], with the amount of exercise necessary differing, dependent on individual factors such as genetics, nutrition and season [11]. Any stallion within a breeding programme should be in good health, with muscle tone maintained by exposing them to turnout or low intensity exercise on a regular basis. Competing stallions exercise more frequently and at higher intensities within training in order to achieve a higher level of performance [12]. It is therefore in the interest of stallion owners to recognise whether consistent high-level competition and repeated exercising of the stallion has a detrimental effect on semen quality and therefore breeding efficiency, potentially leading to a decrease in profit.

Within the human population, males who exercise regularly and live a healthy balanced lifestyle have better quality semen than those not exercising on a regular basis [13]. Exercise and other stressors can influence human endocrinology and fertility [14], with links to improved libido and a positive effect on hormone levels [15]. Physical activity increases the male anabolic hormone environment and therefore an increase in semen production occurs [16]. Semen parameters significantly decline with long-term strenuous exercise when compared with those exercising at moderate intensities [17]. Once exercise is reduced, impairments seen within the reproductive system gradually recover. Similar research suggests that intensity and volume of exercise is negatively correlated to seminal quality, concluding that careful attention should be paid to these variables when designing training programmes to ensure reproductive function is not compromised $[18,19]$.

Limited research of the effects of intense exercise on stallion fertility is available; an early study evaluated the effect of controlled exercise on daily semen output in 2-year-old stallions [20]. Whilst no difference between exercised and non-exercised stallions was found, the young age and sexual inexperience of the stallions does not allow conclusions to be

*Corresponding author: Anke Twigg-Flesner, Performance in Equestrian Sport Research Group, Hartpury University Centre, Hartpury College, Gloucestershire GL19 3BE, UK, Tel: 01452702348; E-mail: Anke.Twigg-Flesner@hartpury.ac.uk

Received April 19, 2017; Accepted May 12, 2017; Published May 15, 2017

Citation: Wilson M, Twigg-Flesner A (2017) A Preliminary Comparison of Semen Quality between Competing and Non-Competing Equine Stallions. J Vet Sci Technol 8: 443. doi: 10.4172/2157-7579.1000443

Copyright: $\odot 2017$ Wilson M, et al. This is an open-access article distributed under the terms of the Creative Commons Attribution License, which permits unrestricted use, distribution, and reproduction in any medium, provided the original author and source are credited. 
drawn for mature and established stallions. Moderate intensity exercise, walking for 30 minutes 4 days per week, has since been shown to have no impact on seminal parameters or the endocrinology of the stallion [21]. Elite-level stallion training would deem this research intensity to be very light rather than moderate, reducing the applicability of this research to the wider competing stallion population. Research on Icelandic stallion fertility rates indicated that high intensity training resulted in higher fertility rates than those in moderate intensity exercise or no exercise, with moderate intensities providing the lowest fertility rates [22]. However, this study was based on fertility rates and individual semen parameters and seminal quality were not taken into account. Controversially, where stallions were undergoing intensive exercise, two days per week, significant stress responses were induced, including increases in heart rate, plasma cortisol, lactate and testosterone concentrations [23]. Hence, excessive physical stress has a negative effect on stallion semen viability and productivity for up to one month after intensive periods of exercise.

The lack of research into the effects of competition on spermatozoa and the amount of conflicting studies into the effects of exercise on stallion semen quality suggests further research is needed within this sector of the equine reproductive industry. The identification of optimal competition management of stallions may help to educate owners, riders and grooms with the potential to lead to increased stallion fertility and economic gain.

The aim of this study was to gain a greater understanding of the effect that exercise and competition has on stallion semen quality.

\section{Methods}

This retrospective study used data from past semen collections of stallions that were being used within artificial insemination breeding programmes at two UK based stud farms between 2009 and 2015. Of the 102 stallions selected for participation in the study, 61 were competing and 41 were non-competing. The stallions were aged between 3 and 21 years old, of various breeds. Prior to data collection, all owners/ representatives of the stallions completed the appropriate consent and data protection forms. The stud farms provided data from each stallion, such as: age, breed and level of competition (higher or lower), if applicable. Alongside this, semen quality assessment information was provided which included: volume of the semen sample $(\mathrm{ml})$, progressive motility (\%) of the spermatozoa, concentration of spermatozoa $\left(\times 10^{6} /\right.$ $\mathrm{ml})$ within the sample, the total sperm count $\left(\times 10^{9}\right)$ and the date in which the semen sample had been collected. Stallions were categorised based on whether they were competing or non-competing and further by ages.

Throughout the study period, the stud farms gave access to data from 1130 semen collections, 798 of which were from competing stallions and 332 from non-competing stallions. All of the samples were collected and assessed by DEFRA approved equine artificial insemination technicians at professional stud farms, ensuring at the time of collection animal welfare was not compromised and limiting ethical considerations.

\section{Statistical analysis}

Data were analysed using IBM SPSS (version 24.0). The data within this study were found to be not normally distributed following the Kolmogorov Smirnov test, hence non-parametric statistical tests were to be performed. A series of Mann-Whitney U Tests compared semen volume, concentration, progressive motility and total sperm count between competing and non-competing stallions to determine if a difference existed between the two groups. A Kruskal-Wallis test of difference was used to determine if a difference existed in semen parameters between the stallion's level of competition. A Kruskal-Wallis test was used to identify if any differences occurred between stallion ages and breeds and semen quality. Data are presented as mean \pm S.E.M. A significance value of $\mathrm{P}<0.05$ was used throughout.

\section{Results and Discussion}

Stallion semen quality, in relation to exercise and competition, is not a topic within the equine industry where much research is available. The few studies analysing this association have shown inconsistent results [18-21]. Therefore, the purpose of this study was to investigate stallion semen quality in relation to competition participation and level.

\section{Volume}

The mean average for each seminal parameter was calculated for competing $(n=798)$ and non-competing stallions $(n=332)$. The average values of non-competing stallions ranged from $6.00 \mathrm{ml}$ to $120.00 \mathrm{ml}$ (Figure 1a) and competing stallions ranged from $3.00 \mathrm{ml}$ to $182 \mathrm{ml}$ (Figure 1a). The semen volume was significantly different $(\mathrm{P}=0.000)$ between competing and non-competing stallions.

Values in stallions competing at lower levels of competition $(\mathrm{n}=228)$ ranged from $6.00 \mathrm{ml}$ to $182.00 \mathrm{ml}$ and stallions at higher levels $(\mathrm{n}=570)$
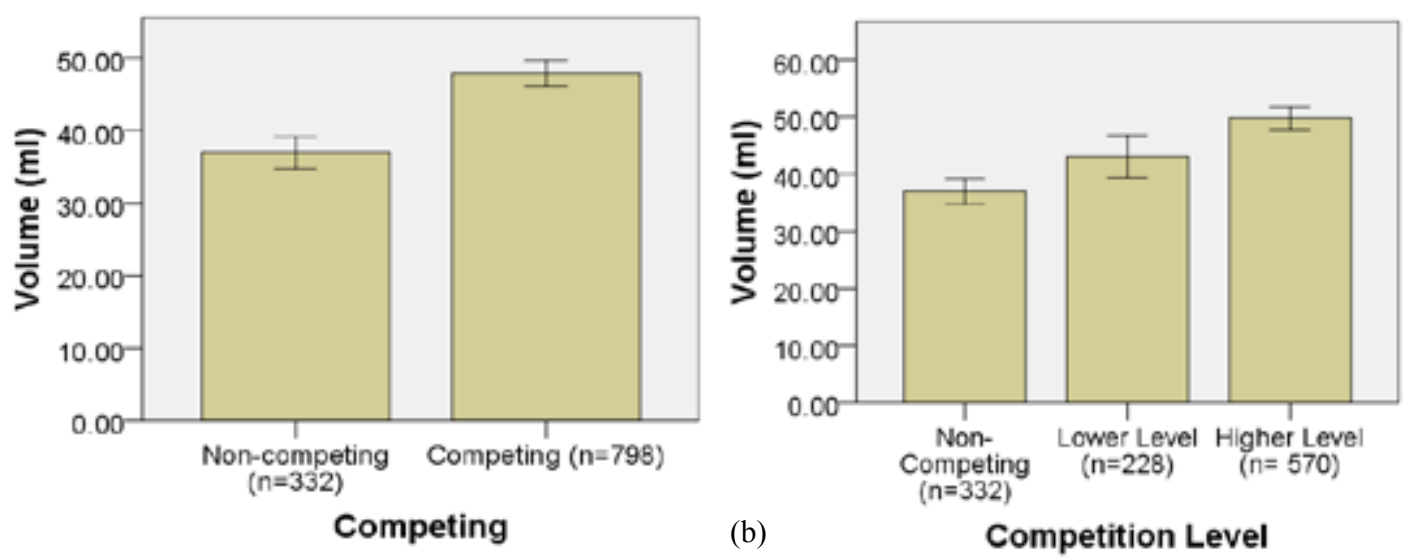

Figure 1: Mean semen volume of (a) competing and non-competing stallions; (b) stallion competition level. Significant $-P<0.05$. 
ranged from $3.00 \mathrm{ml}$ to $180.00 \mathrm{ml}$, with non-competing stallions ( $\mathrm{n}=332)$ ranging from $6.00 \mathrm{ml}$ to $120.00 \mathrm{ml}$ (Figure $1 \mathrm{~b}$ ). Semen volume increased significantly between non-competing and competing stallions, and significantly increased with competition level $(\mathrm{p}=0.000)$.

Research carried out with human participants supports the present findings, stating that physical activity has a significant positive effect on seminological attributes including seminal volume, suggesting the outcome is due to the favourable homeostatic balanced of $\mathrm{LH}$ and testosterone [16,24]. Contrastingly, earlier research found no association between physical activity and semen volume, but as the sample consisted of males that were considered infertile, comparability is reduced [25].

In stallions, improvements in seminal volume are associated with increased teasing [26]. This may be a reason behind the increases in competing stallions due to the collection process differences between the two stud farms, with only one farm using a teaser mare. More concerningly, the mean seminal volumes of both competing and noncompeting stallions were below that of the AI referencing ranges (60-120 $\mathrm{ml})$. Fertility is not directly affected by seminal volume [27]; suggesting that it is more desirable to have lower seminal volumes with higher concentrations of spermatozoa [28]. Therefore, even though lower seminal volumes were observed, the participating stallions may still be sufficiently fertile dependent on the measurements obtained through analysis of additional semen parameters, such as total sperm count and progressively motility, which are considered to be main parameters in semen quality assessment.

\section{Progressive motility}

Values ranged from $1.00 \%$ and $95.00 \%$ in non-competing stallions $(\mathrm{n}=332)$ (Figure 2a) and in competing stallions $(\mathrm{n}=798)$ values ranged from $0.00 \%$ and $85 \%$ (Figure $2 \mathrm{a}$ ). The progressive motility of competing and non-competing stallions was found to be significantly different $(\mathrm{p}=0.011)$.

Progressive motility ranged from from $1 \%$ to $95 \%$ in non-competing stallions ( $\mathrm{n}=332), 10 \%$ to $80 \%$ in stallions at lower levels of competition $(n=228)$ and $0 \%$ to $85 \%$ in higher levels of competition $(n=570)$ (Figure 2b). Statistical analysis revealed a significantly lower progressive motility in competing stallions compared to non-competing stallions $(\mathrm{p}=0.000)$.

The outcomes from this research conform to observations from previous research, which reported a significant decrease in progressive motility of spermatozoa with moderate and high intensity exercise over a prolonged duration, concluding that progressive motility and exercise are negatively correlated [29]. Earlier research also supports these results, stating that training volume has a significant negative correlation to spermatozoa progressive motility, further suggesting that this could be due to low testosterone levels [18]. However, research that is more recent contradicts this, finding testosterone levels increase significantly following exercise and these are positively correlated with progressive motility [30]. Exercise plasma testosterone concentrations were increased, but progressive motility was negatively affected by the intensity of the exercise performed [23].

In humans, lower progressive motility of spermatozoa has been reported within competition periods of endurance athletes, proposing that this could be due to increased intra-scrotal temperatures [31]. Thermal stress has more recently been associated with decreased semen parameters, including progressive motility $[32,33]$. In equine research, thermal stress is a debated topic area with no conclusive results [34], suggesting further research into the effect of testicular thermal stress with regards to semen quality and exercise could be completed.

\section{Concentration}

Values in non-competing stallions $(\mathrm{n}=332)$ ranged from $77 \times 10^{6}$ to $852 \times 10^{6}$ (Figure 3a) Competing stallions' $(\mathrm{n}=798)$ values ranged from $11 \times 10^{6}$ and $811 \times 10^{6}$ (Figure $\left.3 \mathrm{a}\right)$. A significant reduction in sperm concentration $(\mathrm{P}=0.000)$ was found between non-competing and competing stallions. Sperm concentration significantly decreased as competition level increased ( $\mathrm{p}=0.000$ ) (Figure $3 \mathrm{~b}$ ).

The results of this research support findings within human studies, showing decreases in semen concentration of men under high intensity exercise programmes [35]. Semen concentration was impaired with long term, moderate and high intensity exercise, with a decline from a $57.1 \mathrm{million} / \mathrm{ml}$ baseline to $21.7 \mathrm{million} / \mathrm{ml}$ at the lowest point [29] Hence, it was concluded the intensity of exercise and semen parameters are negatively correlated. Research in ovine reproduction supports this, reporting that prolonged daily exercise negatively affects semen concentration is negatively [36].

Suggesting these effects could be due to declined testosterone levels and increases in cortisol, as, more recently, a significant decrease in spermatozoa concentration within males over long durations of high intensity exercise has been reported [37]. This would support previous research findings that psychological stress causes imbalances of the endocrine system which has negative implications on semen quality $[38,39]$. It was also hypothesised that decreases in seminal concentration could be caused by increases of seminal reactive oxygen species (ROS) following exercise [37,40]. Although ROS damage of spermatozoa
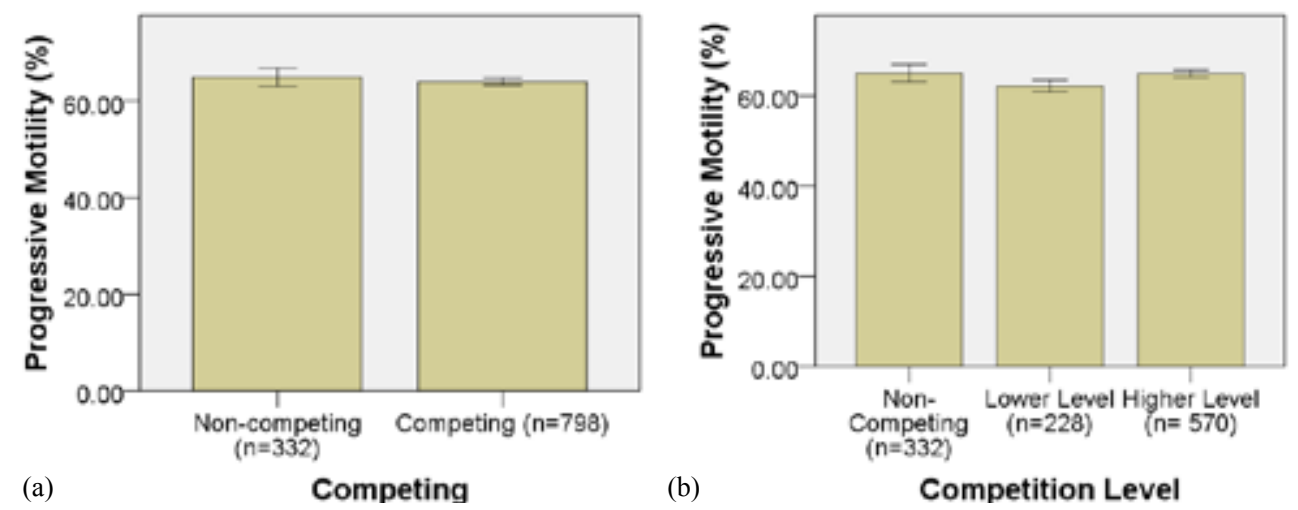

Figure 2: Mean progressive motility of (a) competing and non-competing stallions; (b) stallion competition level. Significant $-P<0.05$. 
with regards to seminal processing has been researched [41-43]; limited research investigating the effects of exercise and ROS damage in equine semen is available. In humans, sufficiently elevated levels of ROS to disrupt reproductive functions are seen following exercise [40]. However, equine research has not established adverse ROS levels, as only limited increases have been reported, which are unlikely to have significant effects on seminal quality [44]. The potential effects of oxidative stress on stallion semen require further contextualisation in order to understand the impact of elevated ROS levels.

Concerningly, all groups contained stallions, which were well under the minimum referencing ranges for artificial insemination (100-350 $\times 10^{6} / \mathrm{ml}$ ). Therefore, would be classed as infertile, posing the ethical questions as to whether these stallions should be part of a breeding programme.

\section{Total sperm count}

The total sperm count values for competing stallions ranged from $0.38 \times 10^{9}$ and $39.00 \times 10^{9}$. The minimum value for non-competing stallions was $1.06 \times 10^{9}$ and the maximum value was $60.24 \times 10^{9}$. A significant difference $(\mathrm{p}=0.000)$ between competing $(\mathrm{n}=798)$ and noncompeting $(n=332)$ stallions' total sperm count was found (Figures $4 \mathrm{a}$ and $4 \mathrm{~b}$ ). A significant reduction in total sperm count occurs between non-competing and competing stallions, but moderate competition values were significantly lower than higher level competition total sperm counts $(\mathrm{p}=0.000)$.
The total number of spermatozoa in a stallion's ejaculate typically ranges from $3 \times 10^{9}$ to $20 \times 10^{9}$. Within the current research, values under these ranges were observed in both competing and non-competing stallions. It is important to consider that these stallions are used in artificial insemination programmes, where the minimum doses are 600 $\times 10^{6}, 300 \times 10^{6}$ and $250 \times 10^{6}$ total progressively motile spermatozoa in chilled, fresh and frozen semen respectively [27]. Therefore, provided minimum progressive motility standards were met, the stallions would be classed as fertile within a commercial artificial insemination programme.

The results of the current study are similar to previous research within human reproduction which established that intense training and competition correlates to decreases in total number of spermatozoa within an ejaculate. Recreationally active athletes are found to have the highest total sperm count [45], in contrast with the results in the present study. Other conflicting research states that higher levels of physical exertion increase spermatozoa numbers [46]. The inconsistencies in current human research that explores the effects of exercise on total sperm count, highlights the need for further research of the impact of exercise intensity on stallion semen quality.

\section{Semen quality}

Semen quality depends on biological, environmental and management practices within the stallion. In order to calculate semen quality and the reproductive capability of a stallion many seminal parameters can be taken into account [47-49]. This study only reports
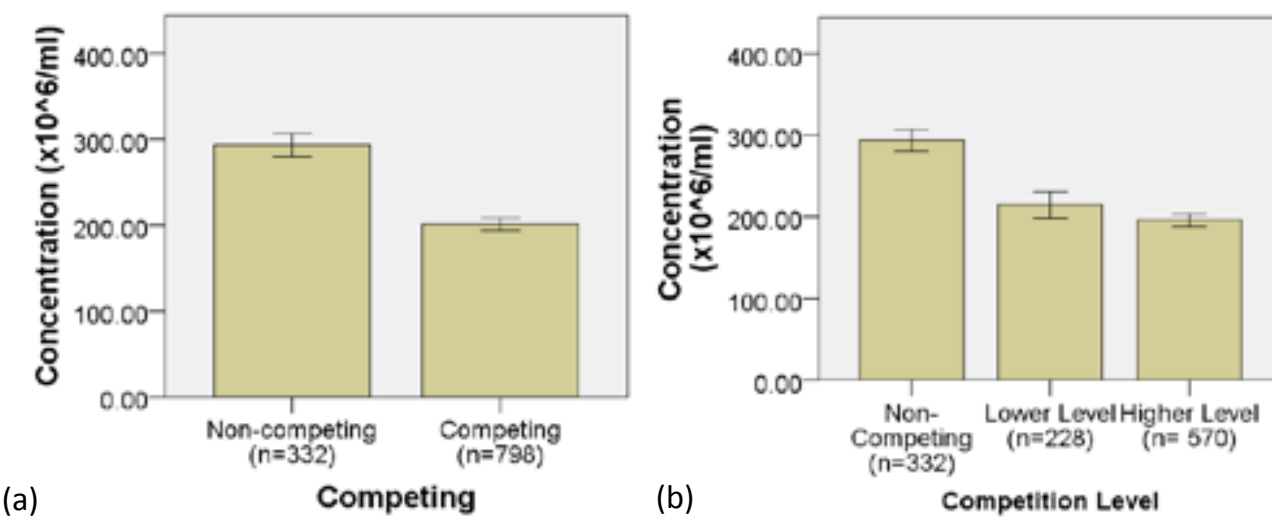

Figure 3: Mean semen concentration of (a) competing and non-competing stallions; (b) stallion competition level. Significant $-P<0.05$.

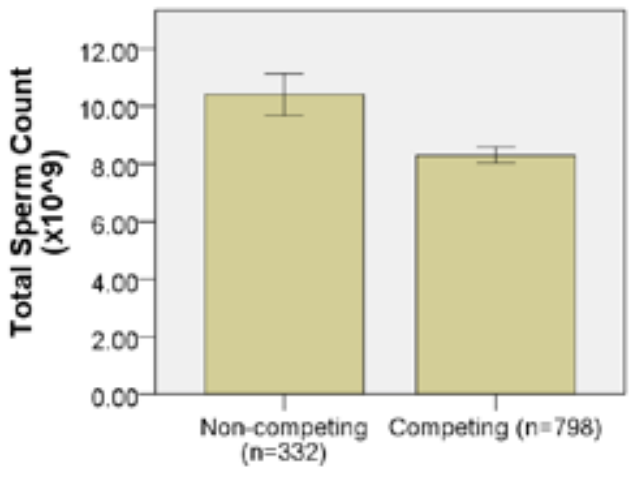

(a)
Competing

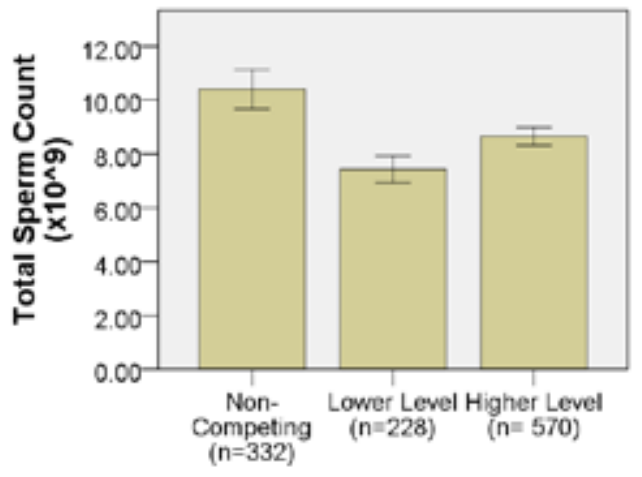

(b)

\section{Competition Level}

Figure 4: Mean total sperm count of (a) competing and non-competing stallions; (b) stallion competition level. Significant $-P<0.05$. 
on volume, concentration, progressive motility and total sperm count as a measure of semen quality. Therefore, competing stallions have lower semen quality than non-competing stallions due to lower mean values of spermatozoa concentration, progressive motility and total sperm count. It should however be taken into account that stallion semen parameters do not necessarily correlate to stallion fertility, with conventional assessment of semen not capturing $100 \%$ of the fertilising potential of spermatozoa [50]. It is suggested that the assessment of many seminal attributes and the combination of results will improve the reliability of fertility prediction $[51,52]$. Within industry spermatozoa morphology is used to observe defects in the physiology of the spermatozoa $[1,53]$ and, along with bacterial status, is seen as a key parameter when predicting the fertilising potential of semen $[1,54,55]$. The most important measurements for estimating stallion fertility is total sperm count alongside progressively motility.

Due to the retrospective design of this study, access to these factors was not available and many of the above semen parameters that could have assisted with the validation of seminal quality were not recorded. Further research should therefore consider the analysis of a wider range of seminal attributes to overcome this limitation.

The retrospective design of the current study meant a lack of standardisation compared to that of controlled experiments. The control of these variables would be unrealistic due to the individual needs of the stallions. The current study may lack standardisation due to these variables, but it allows for a true representation of the industry.

\section{Breed type and age}

Confounding variables such as management protocols, diet, collection technique and environmental factors could have had potential effects on the results obtained [54,55]. Stallion semen parameters are shown to vary significantly dependent on breed and age [56], both of which were confirmed within the present research.
There were significant differences $(\mathrm{p}=0.000)$ across all parameters between age categories, although no linear trends were identified, and changes for each parameter followed a different pattern for the different age groups (Table 1). The most notable finding is the reduction in mean concentration in stallions who would be considered to be in their prime in an athletic and reproductive sense (6-10 years). In contrast to previous research, PM was highest in stallions of 16 years and older. Breed type has a significant impact on all semen quality parameters $(\mathrm{p}=0.000)$, although no linear patterns were established (Table 2$)$.

The retrospective design of the current study meant a lack of standardisation compared to that of controlled experiments. Variables which had the potential to effect semen quality such as environmental and management factors were unable to be regulated. The control of these variables would be unrealistic due to the individual needs of the stallions; control was further limited by the retrospective study design. The current study may lack standardisation due to these elements, but it allows for a true representation of the industry. The current results showing significant differences in semen quality between the ages and breeds of the stallion amplifies the importance of taking these factors into consideration when conducting future investigations into this topic area.

\section{Conclusion}

The research indicates that competition stallions had lower quality of semen than non-competing stallions, this may be due to an accumulation of both physiological and endocrinological factors. It is not possible from this research to state the reason behind the results obtained as much of the research into stallion semen quality is conflicting.

In both competing and non-competing stallions some individuals had semen parameters lower than the referencing ranges for AI, this should be a cause for concern within the equestrian breeding industry

\begin{tabular}{|c|c|c|c|c|c|c|}
\hline & & & Volume (ml) & Progressive motility (\%) & Concentration $\left(\times 10^{6} / \mathrm{ml}\right)$ & Total sperm count $\left(\times 10^{9}\right)$ \\
\hline \multirow{10}{*}{ Age } & \multirow{2}{*}{$1-5(n=225)$} & Mean & 34.84 & 64.62 & 248.89 & 7.65 \\
\hline & & S.E.M & 1.25 & 0.94 & 8.97 & 0.30 \\
\hline & \multirow{2}{*}{$6-10(n=598)$} & Mean & 47.80 & 63.46 & 225.76 & 9.40 \\
\hline & & S.E.M & 1.04 & 0.49 & 4.85 & 0.22 \\
\hline & \multirow{2}{*}{$11-15(n=201)$} & Mean & 52.58 & 64.50 & 204.65 & 9.28 \\
\hline & & S.E.M & 1.90 & 0.73 & 7.19 & 0.27 \\
\hline & \multirow{2}{*}{$16-20(n=26)$} & Mean & 40.73 & 67.50 & 261.19 & 10.63 \\
\hline & & S.E.M & 4.30 & 2.71 & 16.37 & 1.40 \\
\hline & \multirow{2}{*}{$21+(n=80)$} & Mean & 30.73 & 68.45 & 238.46 & 7.55 \\
\hline & & S.E.M & 1.55 & 1.57 & 10.83 & 0.57 \\
\hline
\end{tabular}

Table 1: Mean values of semen parameters for each stallion age category.

\begin{tabular}{|c|c|c|c|c|c|c|}
\hline & & & Volume (ml) & Progressive motility (\%) & Concentration $\left(\times 10^{6} / \mathrm{ml}\right)$ & Total sperm count $\left(\times 10^{9}\right)$ \\
\hline \multirow{10}{*}{ Breed } & \multirow{2}{*}{ WB $(n=491)$} & Mean & 51.24 & 65.21 & 190.74 & 8.88 \\
\hline & & S.E.M & 1.07 & 0.51 & 4.10 & 0.20 \\
\hline & \multirow{2}{*}{ Arab $(n=411)$} & Mean & 39.45 & 62.96 & 246.56 & 8.49 \\
\hline & & S.E.M & 1.07 & 0.58 & 6.15 & 0.20 \\
\hline & \multirow{2}{*}{ Native $(n=192)$} & Mean & 42.18 & 65.70 & 283.76 & 10.34 \\
\hline & & S.E.M & 2.19 & 1.17 & 9.75 & 0.55 \\
\hline & \multirow{2}{*}{ TB $(n=19)$} & Mean & 28.21 & 60.26 & 204.42 & 6.21 \\
\hline & & S.E.M & 2.22 & 1.30 & 24.29 & 1.12 \\
\hline & \multirow{2}{*}{ Polo Pony ( $n=17)$} & Mean & 29.59 & 60.88 & 273.82 & 7.95 \\
\hline & & S.E.M & 4.77 & 1.23 & 21.22 & 1.39 \\
\hline
\end{tabular}

Table 2: Mean values of semen parameters for each stallion breed. 
Citation: Wilson M, Twigg-Flesner A (2017) A Preliminary Comparison of Semen Quality between Competing and Non-Competing Equine Stallions. J Vet Sci Technol 8: 443. doi: 10.417/2157-7579.1000443

Page 6 of 7

and more care is needed to ensure only high quality semen is being used within AI programmes to increase fertility rates.

Overall, it has been shown that careful attention needs to be paid to stallion management in order to properly balance exercise and competition with reproduction. Thus, maximal reproductivity is achieved leading to increased economic gain and maintaining high animal welfare standards.

\section{References}

1. Brito LFC (2007) Evaluation of stallion sperm morphology. Clin Tech Equine Pract 6: 249-264.

2. Strickland C (2011) Dual-career stallions: balancing showing and breeding Horse Sport. February, pp: 38-40.

3. Sairanen, J, Katila T, Virtala AM, Ojala M (2011) Effects of racing on equine fertility. Anim Reprod Sci 124: 73-84

4. Lange J, Matheja S, Klug E, Aurich C, Aurich JE (1997) Influence of training and competition on the endocrine regulation of testicular function and on semen parameters in stallions. Reprod Domest Anim 32: 297-302.

5. Manafi M (2011) Artificial insemination in farm animals. Rijeka, Croatia: InTech

6. Colleoni S, Lagutina I, Lazzari G, Rodriguez-Martinez H, Galli C, et al. (2011) New methods for selecting stallion spermatozoa for assisted reproduction. J Equine Vet Sci 31: 536-541.

7. Varner DD, Gibb Z, Aitken RJ (2014) Stallion fertility: A focus on the spermatozoon. Equine Vet J 47: 16-24.

8. Davies Morel MC (2008) Equine reproductive physiology, breeding and stud management. Wallingford: CAB International, UK.

9. Samper JC, Donley S, McKinnon AO, Pycock JF (2003) Equine breeding management and artificial insemination. Can Vet $\mathrm{J} 44: 332$.

10. Fraser AF (2010) The behaviour and welfare of the horse. 2nd edn. $C A B$ International Oxfordshire, UK.

11. Pickett BW (2000) Exercise for the stallion. J Equine Vet Sci 20: 567.

12. Kuipers H, Keizer HA (1988) Overtraining in elite athletes. Sports Medicine 6: 79-92.

13. Homan GF, Davies M, Norman R (2007) The impact of lifestyle factors on reproductive performance in the general population and those undergoing infertility treatment: A review. Hum Reprod Update 13: 209-223.

14. Lange J, Matheja S, Klug E, Aurich C, Aurich JE (1997) Influence of training and competition on the endocrine regulation of testicular function and on semen parameters in stallions. Reprod Domest Anim 32: 297-302.

15. Wogatzky J, Wirleitner B, Stecher A, Vanderzwalmen P, Neyer A, et al. (2012) The combination matters - distinct impact of lifestyle factors on sperm quality: A study on semen analysis of 1683 patients according to MSOME criteria. Reprod Biol Endocrinol 10: 115

16. Vaamonde D, Da Silva-Grigoletto ME, García-Manso JM, Barrera N, VaamondeLemos R (2012) Physically active men show better semen parameters and hormone values than sedentary men. Eur J Appl Physiol 112: 3267-3273.

17. Safarinejad MR, Azma K, Kolahi AA (2008) The effects of intensive, long-term treadmill running on reproductive hormones, hypothalamus-pituitary-testis axis and semen quality: A randomized controlled study. J Endocrinol 200: 259-271.

18. De Souza M, Arce J, Pescatello L, Scherzer H, Luciano A (1994) Gonadal hormones and semen quality in male runners. Int J Sports Med 15: 383-391.

19. Vaamonde D, Da Silva-Grigoletto ME, García-Manso JM, Vaamonde-Lemos R, Swanson RJ, et al. (2009) Response of semen parameters to three training modalities. Fertil Steril 92: 1941-1946.

20. Dinger JE, Noiles EE, Hoagland TA (1986) Effect of controlled exercise on semen characteristics in two-year-old stallions. Theriogenology 25: 525-535.

21. Gordon RK, Mawyer JD, Cavinder CA, Sigler DH, Blanchard TL, et al. (2014) Effects of moderate exercise on semen parameters and serum $\mathrm{LH}$ and cortisol concentrations in stallions. J Equine Vet Sci 34: 65

22. Davies Morel MC, Gunnarsson V (2000) A survey of the fertility of Icelandic stallions. Anim Reprod Sci 64: 49-64.
23. Janett F, Burkhardt C, Burger D, Imboden I, Hässig M, et al. (2006) Influence of repeated treadmill exercise on quality and freezability of stallion semen. Theriogenology 65: 1737-1749.

24. Rosety-Rodriguez M, Rosety JM, Fornieles G, Rosety MA, Diaz AJ, et al. (2014) Home-based treadmill training improved seminal quality in adults with type 2 diabetes. Actas Urol Esp 38: 589-593.

25. Wise LA, Cramer DW, Hornstein MD, Ashby RK, Missmer SA (2011) Physica activity and semen quality among men attending an infertility clinic. Fertil Steril 95: 1025-1030.

26. Sieme H, Katila T, Klug E (2004) Effect of semen collection practices on sperm characteristics before and after storage and on fertility of stallions. Theriogenology 61: 769-784.

27. McKinnon AO (2010) Assisted Reproduction Techniques (ART) in the horse - a review from artificial insemination to cloning. BEVA.

28. Jasko DJ, Martin JM, Squires EL (1992) Effect of insemination volume and concentration of spermatozoa on embryo recovery in mares. Theriogenology 37: $1233-1239$

29. Hajizadeh Maleki B, Tartibian B (2015) Long-term low-to-intensive cycling training: impact on semen parameters and seminal cytokines. Clin J Sport Med 25: $535-540$

30. Cavinder CA, Zoller JL, Briers G, Sigler DH (2010) Sexual behaviour and blood hormone profiles around the time of ejaculation and subsequent sperm characteristics in stallions. Prof Anim Scientist 26: 540-546.

31. Lucia A, Chicharro JL, Perez M, Serratosa L, Bandres F, et al. (1996) Reproductive function in male endurance athletes: sperm analysis and hormonal profile. J Appl Physiol 81: 2627-2636.

32. Lue Y, Wang C, Liu YX, Hikim APS, Zhang XS, et al. (2006) Transient testicula warming enhances the suppressive effect of testosterone on spermatogenesis in adult Cynomolgus monkeys (Macaca fascicularis). J Clin Endocrinol Metab 91: $539-545$

33. Kim B, Park K, Rhee K (2012) Heat stress response of male germ cells. Cell Mol Life Sci 70: 2623-2636.

34. Mawyer JD, Cavinder CA, Vogelsang MM, Sigler DH, Love CC, et al. (2012) Thermoregulation of the testicle in response to exercise and subsequent effects on semen characteristics of stallions. J Anim Sci 90: 2532-2539.

35. Vaamonde D, Da Silva M, Poblador M, Lancho J (2006) Reproductive profile of physically active men after exhaustive endurance exercise. Int J Sports Med 27: 680-689.

36. Thwaites CJ (1995) The comparative effects of undernutrition, exercise and frequency of ejaculation on the size and tone of the testes and on semen quality in the ram. Anim Reprod Sci 37: 299-309.

37. Möstl E, Palme R (2002) Hormones as indicators of stress. Domest Anim Endocrinol 23: 67-74

38. Walker WH (2009) Molecular mechanisms of testosterone action in spermatogenesis. Steroids 74: 602-607.

39. Gondim FJ, Zoppi CC, Reis Silveira L dos, Pereira-da-Silva L, Vaz de Macedo D (2009) Possible relationship between performance and oxidative stress in endurance horses. J Equine Vet Sci 29: 206-212.

40. Ball B (2000) The effect of oxidative stress on equine sperm function, semen storage and stallion fertility. J Equine Vet Sci 20: 95-96.

41. Ball BA (2008) Oxidative stress, osmotic stress and apoptosis: Impacts on sperm function and preservation in the horse. Anim Reprod Sci 107: 257-267.

42. Aitken RJ, Lambourne S, Gibb Z (2014) The John Hughes memorial lecture: Aspects of sperm physiology - oxidative stress and the functionality of stallion spermatozoa. J Equine Vet Sci 34: 17-27.

43. Andriichuk A, Tkachenko $\mathrm{H}$, Tkachova I (2016) Oxidative stress biomarkers and erythrocytes hemolysis in well-trained equine athletes before and after exercise. J Equine Vet Sci 36: 32-43.

44. Hajizadeh Maleki B, Tartibian B, Eghbali M, Asri-Rezaei S (2012) Comparison of seminal oxidants and antioxidants $n$ subjects with different levels of physical fitness. Andrology 1: 607-614.

45. Gaskins AJ, Mendiola J, Afeiche M, Jorgensen N, Swan SH, et al. (2015) Physical activity and television watching in relation to semen quality in young men. Br J Sports Med 4: 265-270. 
Citation: Wilson M, Twigg-Flesner A (2017) A Preliminary Comparison of Semen Quality between Competing and Non-Competing Equine Stallions. J Vet Sci Technol 8: 443. doi: 10.417/2157-7579.1000443

46. Graham JK (2001) Assessment of sperm quality: A flow cytometric approach. Anim Reprod Sci 68: 239-247.

47. Kastelic J, Thundathil J (2008) Breeding soundness evaluation and semen analysis for predicting bull fertility. Reprod Domest Anim 43: 368-373.

48. Věžník Z, Švecová P, Zajícová A, Přinosilová P (2004) Repetitorium: Spermatology and Andrology and Sperm Analysis Methodology (in Czech). Brno, Czech Republic, p: 197.

49. Magistrini M, Vidament M, Clement F, Palmer E (1996) Fertility prediction in stallions. Anim Reprod Sci 42: 181-188.

50. Colenbrander B, Gadella B, Stout T (2003) The predictive value of semen analysis in the evaluation of stallion fertility. Reprod Domest Anim 38: 305-311.

51. Rodriguez-Martinez H (2003) Laboratory semen assessment and prediction of fertility: Still utopia? Reprod Domest Anim 38: 312-318.
52. Love CC (2011) Relationship between sperm motility, morphology and the fertility of stallions. Theriogenology $76: 547-557$.

53. Samper JC, Pycock JF, Estrada A (2004) Evaluation of the stallion for artificial insemination with cooled shipped semen. Equine Vet Educ 16: 144-149.

54. Contri A, De Amicis I, Molinari A, Faustini M, Gramenzi A, et al. (2011) Effect of dietary antioxidant supplementation on fresh semen quality in stallion. Theriogenology 75: 1319-1326.

55. Brinsko SP, Varner DD, Love CC, Blanchard TL, Day BC, et al. (2005) Effect of feeding a DHA-enriched nutriceutical on the quality of fresh, cooled and frozen stallion semen. Theriogenology 63: 1519-1527.

56. Gottschalk M, Sieme H, Martinsson G, Distl O (2015) Analysis of breed effects on semen traits in light horse, warmblood, and draught horse breeds. Theriogenology 1: 1-7. 